\title{
Correction to: Proceedings of the 3rd RILEM Spring Convention and Conference (RSCC 2020)
}

Isabel B. Valente, António Ventura Gouveia, and Salvador J. E. Dias

\section{Correction to:}

I. B. Valente et al. (eds.), Proceedings of the 3rd RILEM

Spring Conventionand Conference (RSCC 2020), RILEM

Bookseries 33, https://doi.org/10.1007/978-3-030-76551-4

The original version of the book was published with incorrect initial of the editor "Salvador J. E. Dias" has been corrected.

The book have been updated with the change. 